\title{
Single-component and fast-curing epoxy resin for liquid composite molding processes
}

\author{
Yiru Wang ${ }^{1,2, a}$, Wangshuang Liu², Yiping Qiu ${ }^{1}$ and Yi Wei \\ 1 Donghua University, College of Textiles, Shanghai 201620, China \\ 2 Donghua University, Center for Civil Aviation Composites, Shanghai, 201620, China.
}

\begin{abstract}
Development of single-component and fast-curing epoxy resins is highly desired for many industry applications. In this work, we report an epoxy system based on diglycidyl ether of bisphenol A (DGEBA) and 1-(2-cyanoethyl)-2-ethyl-4- methylimidazole (1C2E4MIM). The inductive effect of electron-withdrawing cyano group distinctly increases the latency of 1C2E4MIM without sacrificing the curing rate. The results of differential scanning calorimeter (DSC) and dynamic mechanical analysis (DMA) measurements indicate DGEBA/1C2E4MIM epoxy system can be fully cured in $15 \mathrm{~min}$. The rheological, thermal and mechanical properties of DGEBA/1C2E4MIM epoxy system were studied in detail. The results show that the shelf life of this epoxy system is more than 4 days at room temperature and more than 6 months at $-18{ }^{\circ} \mathrm{C}$. The cured epoxy resins show high glass transition temperature $\left(>155^{\circ} \mathrm{C}\right)$, tensile strength $(>80 \mathrm{MPa})$ as well as excellent moist heat resistance. Finally, carbon fiber-reinforced polymer composites (CFRPs) were fabricated using this epoxy system as matrix via vacuum assisted resin infusion (VARI) process. The mechanical properties of CFRPs, including tensile, flexural, compressive and interlaminar shear properties, were investigated.
\end{abstract}

\section{INTRODUCTION}

Carbon fiber-reinforced polymer composites (CFRPs) are increasingly used in many applications that require high-performance light-weight structural materials. For example, CFRPs are regarded as an ideal light-weight substitute to mental in manufacturing electric car body. Likewise, in commercial aircraft industry, the content of advanced composites in Boeing 787 Dreamliner and Airbus A350 amazingly reaches over $50 \mathrm{wt} \%$. For modern high-performance CFRPs, epoxy resins are the most widely utilized thermosetting matrix materials owing to their superior mechanical performance, dimensional stability, adhesion, heat and chemical resistance. $^{[2-4]}$ The traditional epoxy formulation for
CFRPs commonly includes epoxy monomer and hardener (amines or andydrides). Owing to the limited shelf life, the two components have to be stored separately and mixed immediately just prior to use. Compared with two-component epoxy system, single-component epoxy resin can be conveniently operated without weighting and blending processes. In addition, epoxy curing often accounts for a large proportion of the manufacturing cycle of CFRPs, and so fast-curing epoxy system is desired to improve the production efficiency, which is particularly significant in automobile industry. ${ }^{[5,6]}$

In order to reduce the molding time, short curing time and low viscosity are active demand. Many fast curing epoxy resin systems were studied in past years, which can 
be roughly divided into five parts, thiol curing agent, amine curing agent, anhydride curing agent, cationic curing agent and anion curing agent. Thiol curing agent can not be used in liquid molding system due to low mechanical properties, and very short pot time, and most importantly low glass transition temperature, therefore they are generally used in adhesion or coating ${ }^{[7-9]}$. Anhydride curing agent has to take at least $30 \mathrm{~min}$ to complete the curing at $120{ }^{\circ} \mathrm{C}^{[10]}$, which is too long to meet the industrial production line requirements. Except that, the curing temperature of anhydride is higher. Amine curing agent, cationic curing agent and anion curing agent are relatively suitable to liquid fast molding system due to their short curing time and better mechanical properties and thermo properties. Until now, all of epoxy curing agent used in automobile epoxy product line are Amine curing agents ${ }^{[11,12]}$, which including aliphatic amines, alicyclic amines, and aromatic amines. Alicyclic amines and aromatic amines are much more expensive to aliphatic amines. Most of aromatic amines are solid, and have much higher viscosity when mixed with epoxy resin, which is disadvantage to liquid molding. Except that, aromatic amines have higher curing temperature. Aliphatic amine curing agent is currently used in liquid molding automobile industrial line, but there are still many challenges, the biggest challenge is the balance of viscosity and curing time. ${ }^{[13]}$

Imidazoles are a class of typical epoxy hardener. Only a catalytic amount of imidazoles can initiate the curing reaction through nucleophilic and anionic polymerization processes. ${ }^{14,15}$ Due to the high cross-linking density and low content of polar groups, imidazole-cured epoxy resins have an excellent combination of high modulus, good heat and moisture resistance. In general, imidazoles have intrinsic high curing reactivity towards epoxy resins, and the curing behaviors can be facilely tailored by introducing various substituent groups on the imidazole rings. So far, a large amount of imidazole hardeners with different structures has been commercialized, which provides a generous toolbox to develop single-component and fast-curing epoxy system with reasonable shelf life.

In this work, 2E4MIM and 1C2E4MIM were compared as hardener of single-component and fast-curing epoxy resin for liquid composite molding processes.Furthermore, 1C2E4MIM was investigated in curing behaviour, glass transition temperature $\left(T_{\mathrm{g}}\right)$, tensile property and hot-wet properties. Finally, the mechanical properties of carbon fiber reinforced composite by 1C2E4MIM-epoxy resin was tested.

\section{EXPERIMENTS}

\subsection{Materials}

Diglycidyl ether of bisphenol-A (DGEBA) with an epoxy equivalent weight of 182 192 (NANYAEPOXY RESIN). 1-(2-Cyanoethyl)-2-ethyl-4-methylimidazole (1C2E4MIM, cas:23996-25-0) purity 99\% from Huaweiruike company. 2-ethyl-4-methylimidazole (2E4MIM, cas:931-36-2) purity 99\% from Huaweiruike company. T700 carbon fiber plain weave cloth (Zhongfu Shenying Carbon Fiber Co.,Ltd). Peel ply, infusion net, vacuum bag, seal salve, sealing tape, ventilated felt, pipe thread, guid pipe.

\subsection{Sample preparing}

\subsubsection{Preparing of the resin system}

Mix the hardener and epoxy resin by parts with speed $200 \mathrm{r} / \mathrm{min}$ at ambient temperature for $5 \mathrm{~min}$. Then degas the mixture in vacuum drying oven for $15 \mathrm{~min}$ at 45 ${ }^{\circ} \mathrm{C}$.

\subsubsection{Preparing of the neat resin sample}

Pure the disgassed mixture into the aluminum mold cured $20 \mathrm{~min}$ at $120{ }^{\circ} \mathrm{C}$ for level of $4 \mathrm{wt} \%$ 2E4MIM and 4 wt \%, 6 wt \% 1C2E4MIMIM as the hardener. And cured $40 \mathrm{~min}$ at $120^{\circ} \mathrm{C}$ for level of $2 \mathrm{wt} \% 1 \mathrm{C} 2 \mathrm{E} 4 \mathrm{MIM}$ as hardener. The water absorption sample was obtained by putting the cured resin into deionized water for 80 days at $70{ }^{\circ} \mathrm{C}$. The hot-wet property sample was obtained via putting the cured sample into a deionized water at $100{ }^{\circ} \mathrm{C}$ for $48 \mathrm{~h}$.

\subsubsection{Preparing of the carbon fiber composites}

Lay up the plain wave carbon fiber cloth $(30 \mathrm{~cm} \times 30$ $\mathrm{cm})$ on a glass plate, put the infusion net $(29 \mathrm{~cm} \times 29 \mathrm{~cm})$ on the clothes at the centre, the inlet and outlet pipe 
respectively in each side of the carbon fiber cloth. The ventilated felt was put on the outlet side. The outlet pipe was connected with vacuum pump, with a safety resin trap between them. The vacuum bag was put on the top sealed by sealing tape. Heating the degassed mixture to different temperature inject into the carbon fiber preform. Subsequently cured $30 \mathrm{~min}$ at $120^{\circ} \mathrm{C}$.

\subsection{Measurements}

\subsubsection{Pot life}

The viscosity was obtained by Dynamic Shear Rheometer (DSR) (Rheometer: MARS60) at $25^{\circ} \mathrm{C}, 1.592$ $\mathrm{Hz}$.

\subsubsection{Curing behaviour}

The curing time was tested by DSR and Differential Scanning Calorimeter (DSC) (NETZSCH DSC214). Isothermal DSC studies were performed by rapidly ramping the sample from $0{ }^{\circ} \mathrm{C}$ to $120^{\circ} \mathrm{C}$, with the rate of $100{ }^{\circ} \mathrm{C} / \mathrm{min}$, holding for various periods of time. Dynamic scans at $10{ }^{\circ} \mathrm{C} / \mathrm{min}$ over a temperature range from $25{ }^{\circ} \mathrm{C}$ to $220{ }^{\circ} \mathrm{C}$ was used to determine the total heat of reaction.

\subsubsection{Mechanical properties}

The $\mathrm{Tg}$ and hot-wet glass transition temperature (HW-Tg) were measured by dynamic mechanical analysis (DMA)(TA Q800) at a heating rate of $10^{\circ} \mathrm{C} / \mathrm{min}$. The neat resin mechanical properties were tested according to ASTM by Instron 2360. The tensile properties and flexural properties were tested per ASTM D 638 and ASTM D 790. To evaluate the CFRPs mechanical properties, the T700 plain weave carbon fabric reinforced composite mechanical properties were tested according to ASTM. The casting time and mechanical properties at difference casting temperature have been measured.

\section{RESULTS AND DISCUSSIONS}

\subsection{Comparison of 1C2E4MIM and 2E4MIM as hardener}

3.1.1 Pot life of 1C2E4MIM and 2E4MIM as the hardener

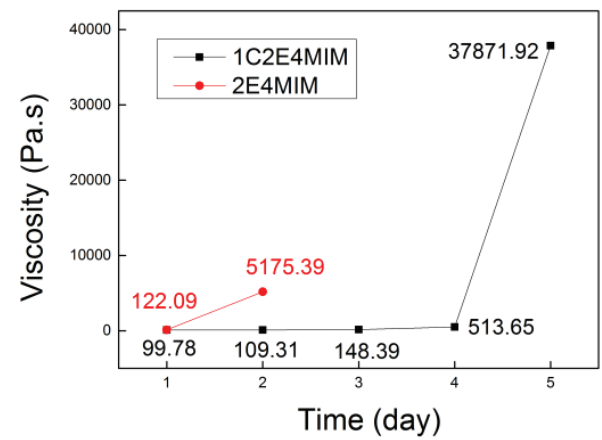

Figure 1. The viscosity change of 1C2E4MIM and 2E4MIM at $25{ }^{\circ} \mathrm{C}$ for five days.

The viscosity of 2E4MIM climbed steeply in the next day, while the 1C2E4MIM increased slightly (figure 1). The 2E4MIM was cured at the third day. The viscosity of 1C2E4MIM climbed much slower than 2E4MIM, which indicate that the thermal latency of 1C2E4MIM was better than 2E4MIM own to the cyano group not only has steric effect, but also has coordination effect with imidazole ring.

\subsubsection{The DMA result of 2E4MIM and 1C2E4MIM as} the hardener

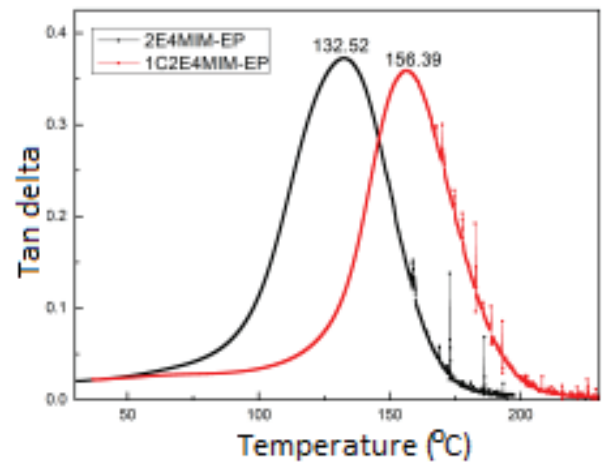

Figure 2. The $T_{\mathrm{g}}$ of $2 \mathrm{E} 4 \mathrm{MIM}$ and $1 \mathrm{C} 2 \mathrm{E} 4 \mathrm{MIM}$ as hardener individually at same content on $4 \%$.

1C2E4MIM had higher $T_{\mathrm{g}}$ than 2E4MIM which could attribute to the cyano group reacted with epoxy group, therefore increased the cross-linking density (figure 2)

\subsubsection{Flexural properties of 2E4MIM and 1C2E4MIM} as the hardener 


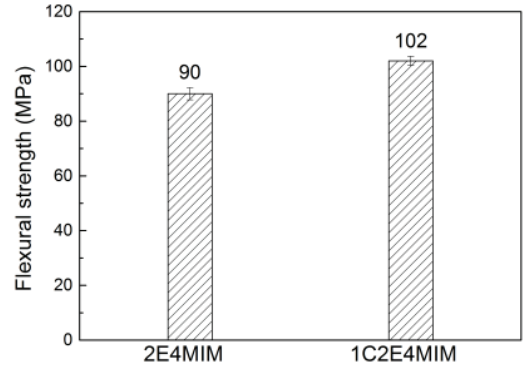

Figure 3. The flexural properties of 2E4MIM and 1C2E4MIM as hardener individually at same content on $4 \mathrm{wt} \%$.

The 1C2E4MIM has higher flexural strength compares to 2E4MIM. The higher flexural strength of 1C2E4MIM also own to higher cross-linking of presence of cyano group (figure 3).

Considering the pot life, $T_{\mathrm{g}}$ and bending properties, the 1C2E4MIM has better performance as a RTM resin of fiber reinforced composite. The properties of 1C2E4MIM as hardener were investigated further.

\subsection{Comparison of different 1C2E4MIM level}

\subsubsection{Curing behaviour of different 1C2E4MIM level}
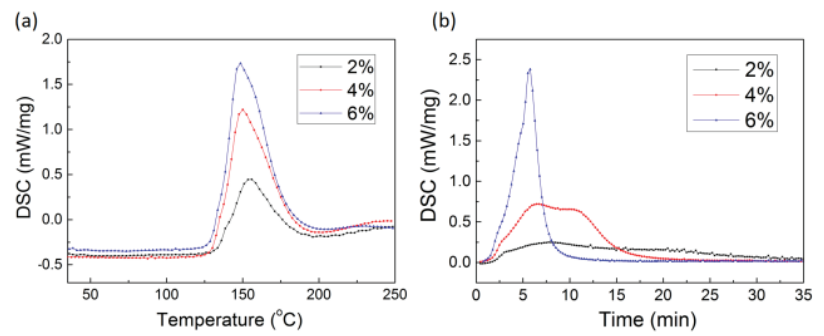

Figure 4. a. DSC curves of the DGEBA/1C2E4MIM system with the different level of 1C2E4MIM at 2 wt \%, 4 wt \%, 6 wt \%: a. on heating rate of $10{ }^{\circ} \mathrm{C} / \mathrm{min}, \mathrm{b}$. on constant temperature on $120^{\circ} \mathrm{C}$.

Table 1. Curing parameters for epoxy compositions on different level of 1C2E4MIM .

\begin{tabular}{|c|c|c|c|c|c|}
\hline $\begin{array}{c}\text { 1C2E4MIM } \\
\text { content } \\
\text { (pbw) }\end{array}$ & $\begin{array}{c}\mathbf{T}_{\mathbf{i}} \\
\left({ }^{\mathbf{0}} \mathbf{C}\right)\end{array}$ & $\begin{array}{c}\mathbf{T}_{\max } \\
\left({ }^{\circ} \mathbf{C}\right)\end{array}$ & $\Delta \mathbf{H}(\mathbf{J} / \mathbf{g})$ & $\begin{array}{c}\text { Curing time } \\
\text { at 120 }{ }^{\circ} \mathbf{C} \\
(\mathbf{m i n})\end{array}$ & $\begin{array}{c}\boldsymbol{T}_{\mathbf{g}}\left({ }^{\circ} \mathbf{C}\right) \\
\text { by DMA }\end{array}$ \\
\hline $2 \%$ & 135.1 & 155.1 & 128.8 & 27 & 71.61 \\
\hline $4 \%$ & 135.0 & 149.4 & 267.5 & 15 & 156.39 \\
\hline $6 \%$ & 134.3 & 147.5 & 334.4 & 8 & 165.06 \\
\hline
\end{tabular}

The increasing of 1C2E4MIM level have no impact on initial curing temperature, but significant impact on heat release and curing time (table 1). The increase of 1C2E4MIM level sharply increased the heat release and decreased curing time (figure 4).

\subsubsection{The DMA result of different 1C2E4MIM level}

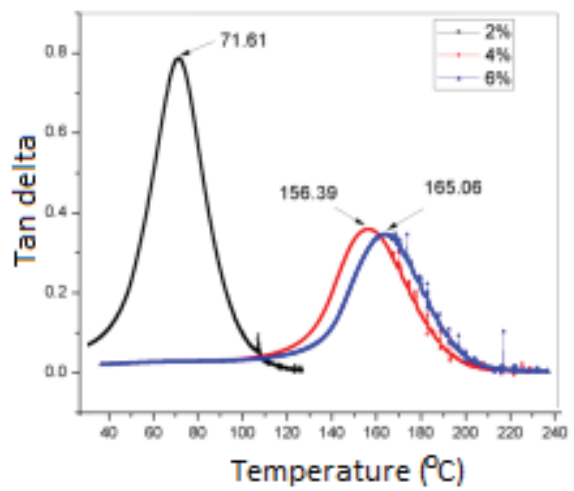

Figure 5. DMA result of different level of 1C2E4MIM at 2 wt $\%, 4$ wt $\%, 6$ wt $\%$

When increased the 1C2E4MIM load, the $T_{\mathrm{g}}$ improved significantly while 1C2E4MIM concentration under $4 \mathrm{wt} \%$, but not that remarkable while 1C2E4MIM concentration above 4 wt $\%$ (figure 5), therefore the $4 \mathrm{wt} \%$ was investigated as the typical concentration.

\subsubsection{Tensile properties of different 1C2E4MIM level}
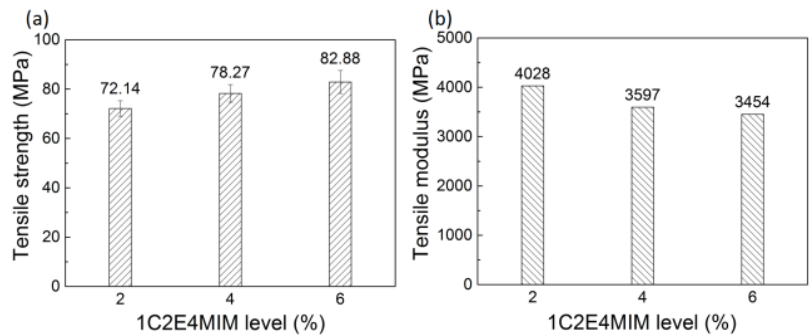

Figure 6. Comparison of neat resin with different level of $1 \mathrm{C} 2 \mathrm{E} 4 \mathrm{MIM}$ at $2 \mathrm{wt} \%, 4 \mathrm{wt} \%, 6 \mathrm{wt} \%$,and PTPA (a) tensile strength, (b) tensile modular.

The tensile strength did not increase much when 1C2E4MIM content was above 4 wt \%, while the tensile modular decreased when 1C2E4MIM increasing (figure 6).

\subsubsection{CFRPs mechanical properties}

The CFRPs mechanical properties with 4 wt \% level of 1C2E4MIM based and T700 plain weave carbon fiber reinforced composite showed high mechanical properties, which 
could meet the load bearing structure requirements.

Table 2. Carbon fiber reinforced 1C2E4MIM-epoxy resin composites mechanical properties.

\begin{tabular}{|c|c|c|c|c|c|}
\hline \multicolumn{2}{|c|}{ Tensile property } & \multicolumn{2}{c|}{ Flexural property } & \multicolumn{2}{c|}{ Compress property } \\
\hline $\begin{array}{c}\text { Strength } \\
\text { (M Pa) }\end{array}$ & $\begin{array}{c}\text { Modular } \\
\text { (G Pa) }\end{array}$ & $\begin{array}{c}\text { Strength } \\
\text { (M Pa) }\end{array}$ & $\begin{array}{c}\text { Modular } \\
\text { (G Pa) }\end{array}$ & $\begin{array}{c}\text { Strength } \\
\text { (M Pa) }\end{array}$ & $\begin{array}{c}\text { Modular } \\
\text { (G Pa) }\end{array}$ \\
\hline 632 & 69 & 662 & 55 & 310 & 60 \\
\hline \multicolumn{6}{|c|}{ Short beam shear strength (M Pa) } \\
\hline \multicolumn{6}{|c|}{43} \\
\hline
\end{tabular}

\section{CONCLUSIONS}

The 2E4MIM and 1C2E4MIM were investigated as fast cure thermal latent epoxy resins, which could be used in automobile production line. The Stern effect and coordination effect on formidable ring of 1C2E4MIM bring better thermal latency and longer pot life. The higher cross-linking with epoxy resin created higher $T_{\mathrm{g}}$, bending strength. It could be deduced that the latency of the electron deficiency group on formidable ring which could react with epoxy group can both improved the latency and properties. Then the properties of different content of 1C2E4MIM were investigated. The when the content below the $4 \mathrm{wt} \%$, the $T_{\mathrm{g}}$ sharp fell, and curing time last long, when the content above $4 \mathrm{wt} \%$, the $\mathrm{Tg}$ climbed very slow, but the heat of reaction were increased and got too high. The hot-wet properties of 1C2E4MIM-Epoxy resin were excellent. And the mechanical properties of $\mathrm{T} 700$ carbon fiber reinforced 1C2E4MIM-Epoxy composites result to be auspicious.

\section{Reference}

1. Fuchs, E., et al. (2008). "Strategic materials selection in the automobile body: Economic opportunities for polymer composite design." Composites Science and Technology 68(9): 1989-2002.

2. Ellis, B. (1993). "Chemistry and technology of epoxy resins." Springer-Science+Business Media, B.V.

3. Ellis, B. (1993). "Chemistry and technology of epoxy resins." Springer-Science+Business Media, B.V.

4. Bauer, R. S. (1985). "Epoxy Resins." ACS SYMPOSIUM SERIES 285: 931-961.

5. Global and China Epoxy Resin Industry Report, 2013-2016,http://www.researchandmarkets.com/re ports/2669198/global_and_china_epoxy_resin_indu stry_report\#pos-3

6. Friedrich, K. and A. A. Almajid (2012). "Manufacturing Aspects of Advanced Polymer Composites for Automotive Applications." Applied Composite Materials 20(2): 107-128.

7. Guzmán, D., et al. (2015). "Enhancement in the Glass Transition Temperature in Latent Thiol-Epoxy Click Cured Thermosets." Polymers 7(4): 680-694.

8. Parker, S., et al. (2016). "High-Tg Thiol-Click Thermoset Networks via the Thiol-Maleimide Michael Addition." Macromol Rapid Commun 37(13): 1027-1032.

9. Parker, S., et al. (2016). "High-Tg Thiol-Click Thermoset Networks via the Thiol-Maleimide Michael Addition." Macromol Rapid Commun 37(13): 1027-1032.

10. Mahendran, A. R., et al. (2011). "Thermal cure kinetics of epoxidized linseed oil with anhydride hardener." Journal of Thermal Analysis and Calorimetry 107(3): 989-998.

11. Fast-curing epoxy system, Automotive Engineering Magazine[EB/OL],01-Oct-2012 08:45 EDT.Available: http://articles.sae.org/11435/

12. DOW, Solutions from Dow Automotive Systems VORAFORCE 5300 ultra-fast cure composite epoxy system.2015.3.25.

13. CompositesWorld, North America is fastest-growing market for automotive lightweight materials [EB/OL], 2015.5.4, Available: http://www.composi -tesworld.com/news/north-america-is-fastest-growi ng-market-for-automotive-lightweight-materials.

14. S.K. Ooia, et al. (2000). "DSC studies of the curing mechanisms and kinetics of DGEBA using imidazole curing agents." Polymer 41: 3639-3649.

15. Heise, M. S. and G. C. Martin (1987). "Curing Mechanism and Thermal Properties of Epoxy-Imidazole Systems." Macromolecules. 